\title{
Zerfall und Leben der Blutplättchen.
}

\author{
Von
}

Dr. H. Deetjen.

(Aus dem Institut für Krebsforschung, Heidelberg.)

(Der Redaktion zugegangen am 25. September 1909.)

Wirkung von Alkali und Säure auf die isolierten Blutplättchen.

Von allen Formbestandteilen des Blutes zeichnen sich die Blutplättchen durch ihren raschen Zerfall nach Verlassen des Blutes aus den Gefäßen aus. Weder die roten noch die weißen Blutkörperchen zeigen diese Erscheinung; die Angabe von A. Schmidt, daß auch die weißen Blutkörperchen außerhalb der Gefäße rapide zugrunde gingen, haben die neuerenUntersuchungen nicht bestätigen können. Über die Ursache des Zerfalls der Blutplättchen wußten wir bisher eigentlich nur, daß sie in einem Zusammenhang mit der Blutgerinnung stehen müsse, da alle Mittel, welche diese verhinderten, auch die Blutplättchen vor dem Untergange schützten. ${ }^{1}$ ) Bei der von mir früher aufgestellten Annahme, daß die Blutplättchen nicht einfach Degenerationsprodukte, sondern kernhaltige, bewegungsfähige Elemente seien, mußte es von besonderem Interesse sein, über die Ursache des Zerfalls und deren Zusammenhang mit der Gerinnung größere Klarheit zu bekommen. Die Untersuchungen hierüber sind ausschließlich an Menschenblut vorgenommen und haben nur für menschliche Blutplättchen Gültigkeit, da die Blutplättchen der Tiere zum Teil sich ganz anders verhalten.

Es war zunächst notwendig, die Blutplättchen zu isolieren. Dies gelingt am einfachsten in der Weise, daß man ein Tröpfchen

1) Cf. Bürker, Blutplättchen und Blutgerinnung. Arch. f. d. ges. Physiol., Bd. GII, S. 36.

Hoppe Seyler's Zeitschrift f. physiol. Chemie. LXIII. 
Blut aus der Fingerbeere entnimmt, auf einem Deckgläschen auffängt und dieses auf einen Objektträger bringt, auf den man vorher zweckmäßig zwei dünne Glasfäden parallel nebeneinander aufgelegt hat. Nun schwemmt man sofort das Blut fort, indem man von der einen Seite mit einer Pipette physiologische Kochsalzlösung zufließen läßt und von der entgegengesetzten Seite mit Filtrierpapier absaugt. Sowohl die roten wie die weißen Blutkörperchen werden hierdurch fortgespült, nur die Blutplättchen bleiben vermöge ihrer Klebrigkeit, wenigstens zum größten Teil am Glase haften. Die Methode hat den großen Vorteil, daß man nacheinander nun die verschiedensten Lösungen auf die Blutplättchen einwirken lassen und das Verhalten der Plättchen in ihnen beobachten kann.

Über die Art der Reinigung der benutzten Gläser werde ich am Schlusse der Arbeit noch einiges sagen. Es ist notwendig, besondere Aufmerksamkeit darauf zu verwenden, wenn man gleichmäßige Resultate erzielen will.

Wenn man die Blutplättchen in der angegebenen Weise auf Objektträger und Deckglas aus gewöhnlichem Glas mit einer ohne besondere Vorsichtsmaßregeln hergestellten 0,9\% igen Kochsalzlösung isoliert, so sieht man sie nach wenigen Minuten zerfallen. Die Art des Zerfalls kann als "typisch • bezeichnet werden, d. h. es ist diejenige, die man auch bei der Gerinnung beobachtet, nur mit dem Unterschied, daß in der Salzlösung der Zerfall rascher vor sich geht und auch wohl zu einer vollständigeren Auflösung führt, als im Blute selbst. Die Plättchen werden dabei rasch unregelmäßig in der Form, eine zarte, hyaline Substanz tritt heraus, die zentrale Kernsubstanz wird körnig und verteilt sich zum Teil im Protoplasma. Der Zerfall schreitet rasch vorwärts, wobei die Blutplättchen sich immer mehr am Glase ausbreiten und schließlich zu kaum sichtbaren, blassen Gebilden werden. Wo Blutplättchen in Haufen zusammenliegen, verkleben sie dicht miteinander. Man kann diese Art des Zerfalls auch als Agglutination bezeichnen.

Verschieden von dieser typischen Form des Zerfalls ist die Veränderung, welche unter dem Einfluß hypotonischer Lösungen oder stärkerer Alkalien stattfindet. Hierbei quellen die 
Plättchen zu kugeligen Blasen mit Randstellung der Kernsub$\operatorname{stanz}$ auf.

Ganz anders verhalten sich die Blutplättchen, wenn man sie nicht zwischen Glas, sondern zwischen Deckglas und Objektträger aus Quarz untersucht und vollkommen alkalifreies Wasser zur Herstellung der physiologischen Kochsalzlösung benutzt. Die Quarzgläser waren von der Firma C. Zeiß-Jena bezogen. Es genügt, als Objektträger krystallinischen Quarz (Bergkrystall) zu nehmen, das Deckglas muß aus geschmolzenem Quarz hergestellt sein, weil sonst die optischen Bedingungen zur Beobachtung zu ungünstig sind, auch darf das Deckglas nicht rund sein, weil die Spülung dann nicht gelingt. Ich benutze ein Deckglas von $18 \mathrm{qmm}$ und etwa $0,2 \mathrm{~mm}$ Dicke.

Vollkommen alkalifreies Wasser gewann ich durch Destillation von schon einmal destilliertem Wasser nach Zusatz von einigen Tropfen verdünnter Schwefelsäure durch ein Quarzrohr ${ }^{1}$ ) unter Vermeidung jeder Kork- oder Kautschukverbindung. Als Destillationskolben wurde eiue gewöhnliche, große, birnförmige Retorte aus Jenaer Glas benutzt, deren Hals etwa zur Hälfte abgesprengt war. In den Hals ragte das Ende des Quarzrohrs, die Mündung der Retorte wurde durch Watte verschlossen. Auf diese Weise kommt der Wasserdampf bei der Kühlung nirgends mit Glas oder fremden Substanzen in Berührung. Das Destillat wurde in sehr gut ausgedämpften Kolben aus Glas oder paraffinierten Gefäßen aufgefangen und nur die mittlere Fraktion zur Herstellung der Lösung benutzt. Außer diesem Wasser habe ich auch das von der Firma Kahlbaum in den Handel kommende Leitfähigkeitswasser verwandt. Das Kochsalz stammte ebenfalls von Kahlbaum. Es war nicht notwendig, dasselbe umzukrystallisieren. Wenn man mit so hergestellter 0,9\% iger Kochsalzlösung die Blutplättchen auf Quarz isoliert, so zerfallen sie nicht, sie verlieren zum Teil ihre Klebrigkeit und schwimmen frei in der Flüssigkeit als ovale oder runde Gebilde, von derselben Form, wie wir sie an den frisch fixierten Präparaten kennen. So bleiben sie stundenlang fast unverändert

1) Quarzrohre aus undurchsichtigem (sogenanntem englischen) Quarz sind zurzeit verhältnismäßig billig zu bekommen. 
und gehen dann allmählich durch Quellung mit Randstellung des Kerns zugrunde.

Es war nach dieser Beobachtung von vornherein wahrscheinlich, daß Alkali eine Rolle beim Zerfall spielen müsse. Das zeigte sich auch sofort, wenn die neutrale Kochsalzlösung eine Spur alkalisch gemacht wurde. Dann zerfallen die Plättchen auf Quarz ebenso rasch wie auf Glas.

Um die Mengen von Alkali oder, besser gesagt, der $\mathrm{OH}$ Ionen, welche zum Zerfall notwendig sind, zu bestimmen, habe ich die von Friedenthal ${ }^{1}$ ) eingeführte Indikatorenmethode benutzt. Diese gibt vollkommen ausreichend genaue Resultate auch bei der Bestimmung der sehr geringen Abweichungen vom Neutralpunkt, welche hier in Betracht kommen, vor allem da es bei unserer Methode sich um Lösungen handelt, die keine starken und schwachen Elektrolyte gemischt enthalten. Man darf sich bei der Bestimmung der OH- resp. H-Ionenkonzentration aber nicht an die Tabellen halten, welche in den neueren Lehrbüchern angegeben sind. Diese halten sich meist an die von Salm aufgestellte Skala, bei welcher durch wechselnde Mengen von Mono- und Dinatriumphosphat die verschiedenen H-Ionenkonzentrationen erzielt sind. Bei der Bestimmung der Reaktion von reinem Wasser wird aber durch den Zusatz der Indikatorsäure die der Dissoziation derselben entsprechende Farbennuance auftreten, worauf schon Friedenthal aufmerksam macht. Man kommt bei den Konzentrationsbestimmungen, die für unsern Fall in Frage kommen, in der Regel mit 2 Indikatoren aus - alizarinsulfosaurem Natrium und Rosolsäure. Der erste Farbstoff gibt mit neutralem Wasser $\left(\mathrm{C}_{\mathrm{H}}=1 \cdot 10^{-7}\right)$ Gelbfärbung, die bei Zusatz von Säure noch etwas heller wird; schon bei Anwesenheit minimaler Mengen von Alkali $\left(\mathrm{C}_{\mathrm{H}}=1 \cdot 10^{-8}\right)$ geht die Farbe in rosa über. Rosolsäure zeigt bei $\mathrm{C}_{\mathrm{H}}=1 \cdot 10^{-8}$ orange, bei $\mathrm{C}_{\mathrm{H}}=1 \cdot 10^{-9}$ rosa Färbung der Lösung. Diese Stufen vom Neutralpunkt bis zur Konzentration der $\mathrm{OH}-$ Ionen, entsprechend einer $1 / 100000-\mathrm{n}-\mathrm{NaOH}$, kommen allein bei der Frage bezüglich der Wirkung der $\mathrm{OH}-$

1) H. Friedenth al, Zeitschrift f. Elektrochemie, 1904, Nr. 8, S. 113. 
Ionen auf die Blutplättchen in Betracht. Zu erwähnen ist noch, daß bei Zusatz von reinem Kochsalz zu neutralem Wasser der Farbenton des alizarinsulfosauren Natriums ein wenig dunkler wird, was aber wohl kaum auf eine Änderung der H-Ionenkonzentration zurückzuführen ist, sondern auf eine Beeinflussung der Farbe durch die Gegenwart des Salzes in dem Sinne, wie es von Michaelis und Rona ${ }^{1}$ ) angegeben wurde. Wenn man bei der Untersuchung auf Quarz die Kochsalzlösung durch Zusatz von verdünnter Natriumbicarbonatlösung so weit alkalisch macht, daß sie, mit Rosolsäure versetzt, gerade eben rosa sich färbt, so zerfallen die Blutplättchen in wenigen Minuten in typischer Weise, nicht dagegen, wenn die Lösung mit Rosolsäure orange, mit alizarinsulfosaurem Natrium aber rot gefärbt wird. Man kann deshalb sagen, daß die Gegenwart von $\mathrm{OH}-$ Ionen in einer Konzentration, entsprechend etwa einer 1/100000-n-NaOH, die Bluttplättchen mit Sicherheit zum Zerfall bringt.

Ebenso wie OH-Ionen wirken auch H-Ionen, nur mit dem Unterschied, daß eine wesentlich höhere Konzentration notwendig ist, um den Zerfall einzuleiten, nämlich eine solche entsprechend einer ${ }^{1 / 20000-n-H C l}$. Geringere Konzentrationen, z. B. 1/100000-n-HCl, ermöglichen dagegen besonders leicht und gut die Darstellung der intakten Blutplättchen.

Es war weiterhin von Wichtigkeit, festzustellen, wie die Anwesenheit von Kalk, bei der bekannten Beeinflussung der Gerinnung durch Kalksalze, wirken würde. Es zeigte sich, daß Zusatz von $\mathrm{CaCl}_{2}(0,02 \%)$ zu vollkommen neutralen Lösungen nichts an dem Verhalten ändert. Die Blutplättchen bleiben intakt. In alkalischen Lösungen geht einmal der Zerfall rascher vor sich, und dann wird der Gehalt an OH-Ionen, welcher notwendig ist, um die Auflösung zu bewirken, herabgesetzt, es genügt dann die Konzentration von $1 \cdot 10^{-8}$ H-Ionen, die durch die beginnende Rotfärbung des alizarinsulfosauren Natriums angezeigt wird, um die Blutplättchen in typischer Weise zum Zerfall $\mathrm{zu}$ bringen.

1) L. Michaelis und P. Rona, Zeitschrift f. Elektrochemie, 1908, Nr. 18, S. 251. 
Es wird nach dem Gesagten einleuchten, warum man bei der Herstellung des destillierten Wassers bei diesen Versuchen besondere Vorsichtsmaßregeln treffen muß, da das käufliche destillierte Wasser in der Regel alkalisch reagiert, besonders dann, wenn durch Glasrohre destilliert wird oder wenn es längere Zeit in Glasflaschen auf bewahrt wird. Statt der Objektträger und Deckgläser aus Quarz kann man auch gewöhnliche gebrauchen, wenn sie gut gereinigt sind, vor allem durch längeres Aufbewahren in Wasser größtenteils ihres oberflächlichen Alkaligehaltes beraubt sind.

Methoden, welche gestatten, die Blutplättchen auch bei Gegenwart von Alkali intakt zu halten.

Die Konzentration der $\mathrm{OH}-I o n e n$, welche den Zerfall der Blutplättchen bewirken, ist so gering, daß es von vornherein unwahrscheinlich war, daß sie direkt zerstörend auf die Plättchen wirken sollten, es war eher anzunehmen, daß ihnen nur eine indirekte Bedeutung zukommen müsse. Das geht auch daraus hervor, daß es eine ganze Anzahl von Methoden gibt, mit Hilfe deren es möglich ist, auch bei Gegenwart von Alkali die Blutplättchen am Leben $z u$ erhalten. Ich werde diese Methoden und ihre Anwendung zunächst besprechen, auf die Erklärung ihrer Wirkungsweise aber erst im nächsten Abschnitt $\mathrm{zu}$ sprechen kommen.

Die erste Methode besteht darin, daß man das Blut mit Blutegelextrakt resp. dem wirksamen Prinzip desselben, dem Hirudin (C. Sachsee \& Co., Leipzig), behandelt. Es ist bekannt, daß das mit Hirudin versetzte Blut nicht gerinnt und die Blutplättchen nicht zerfallen. Wenn man nun aber mit einer Lösung von Hirudin in alkalischer Kochsalzlösung $(0,01: 10,0)$ in der gegebenen Weise die Blutplättchen isoliert, dann zerfallen die Blutplättchen ebenso rasch, wie in alkalischer Salzlösung allein. Die Alkalescenz der physiologischen Lösung wurde in diesem, wie bei allen folgenden Versuchen, durch Zusatz von 0,01\% Natriumbicarbonat zur Lösung bewirkt. Trotzdem die Konzentration des Hirudins in der Lösung verhältnismäßig stark, ist es also unter diesen Bedingungen ganz 
unwirksam. Löst man dagegen das Hirudin in verdünntem Serum vom Menschen (1 Teil frisches Serum zu 20 Teilen physiologischer Kochsalzlösung), dann ist das Hirudin stark wirksam. Es scheint demnach, als ob das Hirudin erst durch eine im Serum befindliche Substanz aktiviert wird. Durch Erhitzen verliert das Serum diese Eigenschaft.

Spült man mit so hergestellten Lösungen das Blut, so bleiben die Plättchen volkommen intakt und unbeweglich. Läßt man die Hirudinlösung noch kurze Zeit (etwa 2 Minuten) auf die Plättchen einwirken, und ersetzt sie dann durch alkalische Kochsalzlösung, so tritt etwas verzögert zwar, aber doch deutlich typischer Zerfall ein.

Läßt man dagegen die Hirudinlösung 10-15 Minuten einwirken, dann ist nachfolgende Spülung mit der alkalischen Salzlösung ohne Einfluß. Auch durch Serum zerfallen die Plättchen dann nicht, wohl aber durch Plasma.

Eine andere Methode, den raschen Zerfall der Blutplättchen zu verhindern, besteht darin, daß man der Kochsalzlösung Salze der Manganreihe, nämlich Mangan, Cobalt oder Nickel zusetzt. Es ist dabei gleichgültig, welche Anionen genommen werden, Sulfate, Nitrate und Chloride der Metalle sind in gleicher Weise wirksam. Ich benutzte meist das Mangansulfat, das sich leicht in Wasser löst. Es scheint fast vollkommen ungiftig für die Zellen des Blutes zu sein, da auch in stärkeren Konzentrationen die Bewegungen der Leukocyten sehr lange andauern.

Der Zerfall der Blutplättchen wird bei Gegenwart dieser Salze in der Spülflüssigkeit $z$ war nicht vollkommen aufgehalten, aber doch sehr verzögert. Spült man mit einer Lösung, die $0,5 \mathrm{~g}$ Mangansulfat und $0,7 \mathrm{~g}$ Kochsalz enthält, so zeigen die Blutplättchen eine Zeitlang deutlich amöboide Bewegungen, auch der Kern ist anfangs gut erkennbar und scharf abgegrenzt. Ganz langsam und allmählich treten dann die weiteren Veränderungen ein, die zur Auflösung führen, wie weiter unten genauer beschrieben werden soll. Die Methode eignet sich deshalb besonders gut, um die einzelnen Phasen des sonst sehr rasch verlaufenden «typischen»Zerfalls zu verfolgen. 
Besonders interessant ist die Beeinflussung der Blutgerinnung durch die Salze der Manganreihe. Durch Zusatz von $0,5 \mathrm{~g}$ Mangansulfat $\mathrm{zu} 100 \mathrm{ccm}$ Blut wird die Gerinnung vollkommen verhindert. Die Gerinnung tritt aber wieder ein, wenn zum Blut oder Plasma Substanzen zugesetzt werden, die das Mangan ausfällen, z. B. Dinatriumphosphat. $\mathrm{Zu} 10 \mathrm{ccm}$ Rinderblut, das durch Zusatz von $0,5 \% \mathrm{MnSO}_{4}$ ungerinnbar gemacht war, wurde $1 \mathrm{ccm}$ normale $\mathrm{Na}_{2} \mathrm{HPO}_{4}$-Lösung gesetzt. Nach 3/4 Stunden war das Blut vollkommen fest geronnen. Das Plasma war etwas später, nach 2 Stunden, fest erstarrt.

Wenn auch die Art der Einwirkung der Mangansalze auf die Gerinnung noch genauerer Prüfung bedarf, so kann man doch vermuten, daß sie auf einer Veränderung des Profermentes beruht, so daß es bei Gegenwart des Mangans trotz Anwesenheit von Kalk und Alkali nicht zur Bildung wirksamen Gerinnungsfermentes kommt. Da die Blutplättchen, wenn auch langsam, in diesem Blut zugrunde gehen, so haben wir die einzige bisher bekannte Ausnahme von der Regel, daßs alle Mittel, welche die Blutgerinnung verhindern, auch die Blutplättchen vor dem Zerfall schützen.

Es ist bemerkenswert, daß durch Zusatz von Mangansalzen flüssig gehaltenes Blut sehr lange frei von Fäulniserscheinungen bleibt, wenn es bei Zimmertemperatur aufbewahrt wird. Das beruht nicht auf der Gegenwart des Mangans. Denn defibriniertes Blut, dem nachträglich Mangansalz zugesetzt wird, fault rasch.

Die dritte Methode der Konservierung der Blutplättchen besteht in der Spülung mit Peptonlösungen, und zwar mit Pepton Witte, mit Pepton sicc. ex albumine Merck gelingt es nicht. In 2\% iger Wittepepton-Kochsalzlösung bleiben die Plättchen 24 Stunden und länger unverändert und unbeweglich. Auch wenn man nach kurzer Einwirkung der neutralen Peptonlösung mit alkalischer Peptonlösung spült, bleiben sie intakt. Es wurde in diesem Fall mit Sodalösung alkalisch gemacht, bis bei Zusatz von Phenolphthalein gerade beginnende Rotfärbung eintrat. Es ist also nicht die Neutralität der Lösung, wie man denken könnte, die den Zerfall aufhält. Spült man aber auch nach 
stundenlangem Stehenlassen in der Peptonlösung mit alkalischer Salzlösung, so tritt Zerfall ein.

Am besten eignet sich für die Untersuchung der Lebensvorgänge der Blutplättchen die vierte Methode. Ich fand zunächst, daß bei Zusatz geringer Mengen von ungesättigten Kohlenwasserstoffen zur Kochsalzlösung die Blutplättchen in ausgezeichneter Weise am Leben erhalten blieben. Nicht nur waren die amöboiden Bewegungen leicht zu erkennen, sondern es konnte auch nach kurzer Behandlung mit den Lösungen weder durch Alkali und Kalk, noch durch Serum das Phänomen des Zerfalls und der Agglutination ausgelöst werden. Da eine große Reihe von ungesättigten Verbindungen, wie Amylen, Hexylen, Allylchlorid, Allylsenföl, Krotonaldehyd u. a. in gleicher Weise wirksam waren, glaubte ich anfangs, daß die Wirkung in dem Vorhandensein einer doppelten Bindung im Molekül, die allen diesen Körpern zukommt, beruhen müsse. Diese Annahme erwies sich aber als unrichtig, denn es zeigte sich, daß ganz frisch hergestellte Lösungen völlig unwirksam waren. Am besten eignet sich für diese Untersuchungen das Amylen $\left.\left(\mathrm{CH}_{3}\right)_{2} \cdot \mathrm{C}=\mathrm{CH} \cdot \mathrm{CH}_{3}\right)$, das leicht dargestellt werden kann. Erst nach längerem Aufbewahren an der Luft und am Licht wurde es aktiv. Man konnte daran denken, daß es Polymerisationsprodukte wären, welche sich bei längerem Aufbewahren bilden, die den wirksamen Körper bildeten. Die durch Behandlung mit Schwefelsäure erhältlichen Di- und Triamylene waren aber ebenfalls ohne Einfluß. Eine andere Umwandlung, die die ungesättigten Verbindungen erleiden, besteht in der Addition von Sauerstoff unter Bildung von Peroxyden. Die Peroxyde der Olefine sind besonders von Engler und Weißberg ${ }^{1}$ ) in letzter Zeit eingehender untersucht. Er nimmt an, daß sich dabei der Sauerstoff in molekularer Form an den doppelt gebundenen Kohlenstoff anlagert, also beim Triamylen in der Weise:<smiles>CC1OOC1C</smiles>

1) C. Engler und J. Weißberg, Kritische Studien über die Vorgänge der Autoxydation. Braunschweig 1904. 
Der so gebundene 0 wird leicht an autooxydable Körper abgegeben. Daß nur diese Peroxyde den aktiven Körper bei unsern Versuchen bilden, geht einmal schon daraus hervor, daß z. B. das Amylen erst beim Aufbewahren an der Luft wirksam wird, und zwar dann, wenn man durch Reagenzien den Nachweis von dem Vorhandensein des Peroxyds liefern kann. Ein sehr empfindliches Reagens ist das Tetramethyldiamidodiphenolmethan (Tetrapapier Merck), das sich bei Gegenwart von Peroxyden blau färbt. Engler zeigte ferner, daß nach dem Abdestillieren des Amylens das Peroxyd zurückbleibt. Man kann nun auch so verfahren, daß man, anstatt das Amylen zur Kochsalzlösung zuzusetzen, einige Tropfen in ein Glas bringt, verdunsten läßt und dann erst die Kochsalzlösung einfüllt. So genügte es, von einem von der Firma Merck gelieferten, etwa ein Jahr alten Amylen 10 Tropfen verdunsten zu lassen und den minimalen Rückstand mit $100 \mathrm{ccm}$ Salzlösung zu übergießen, um eine Lösung zu bekommen, in welcher die Blutplättchen vollkommen am Leben blieben. Endlich kann man auch mit sehr vielen anderen Substanzen, die Peroxyde zu bilden imstande sind, den Zerfall der Plättchen verhindern, so mit Terpentinöl, Leinöl und vor allem mit Wasserstoffsuperoxyd. Eine $0,005 \%$ ige Lösung von Perhydrol (in Kochsalzlösung) gibt ähnliche gute Resultate wie Amylenlösungen. Es ist erstaunlich, wie gut nicht nur Blutplättchen, sondern auch Leukocyten von solchen Lösungen, die doch verhältnismäßig große Mengen von $\mathrm{H}_{2} \mathrm{O}_{2}$ enthalten, am Leben bleiben.

Von den vielen Substanzen, die an dieser Stelle genannt werden können, möchte ich noch eine erwähnen, weil sie sehr leicht zu Irrtümern führen kann, nämlich Kautschuk. Wenn man in das zu destillierende Wasser ein Stückchen Kautschukschlauch wirft, geht ein Destillat über, das noch in starker Verdünnung dieselben Eigenschaften hat wie Peroxydlösungen. Da Kautschuk leicht Sauerstoff addiert, ist anzunehmen, daß die Wirksamkeit auch hier auf der Gegenwart von Peroxyden beruht.

Es gelingt aber nicht, mit Hilfe von Peroxyden die Blutgerinnung $\mathrm{zu}$ verhindern, weder diejenige von frischem Blut, noch die Gerinnung von Oxalatplasma bei nachfolgendem Zusatz 
von Serum. Es wird im Gegenteil die Gerinnung eher beschleunigt nach Zusatz von Amylenperoxyd zum Plasma.

\section{Ursachen des Zerfalls und der Lebenserhaltung der isolierten Blutplättchen.}

Während im ersten Teil der Untersuchungen festgestellt werden konnte, daß die isolierten Blutplättchen bei Gegenwart von $\mathrm{OH}$ - (und eventuell $\mathrm{H}-$ ) Ionen zugrunde gingen, wurde im vorigen Abschnitt gezeigt, daß unter besonderen Bedingungen der Zerfall auch bei Anwesenheit von Alkali verhindert werden kann. Es scheint dies darauf hinzudeuten, daß noch ein zweiter Faktor für den Zerfall in Betracht kommt. Wird dieser ausgeschaltet, so sind die Hydroxylionen unwirksam. Über die Natur dieser anderen Substanz geben die Hirudinversuche am besten Aufschluß. Es war gesagt worden, daß mit Hirudinlösungen 10-15 Minuten behandelte Blutplättchen weder durch Alkali und Kalk, noch durch Serum zugrunde gingen, wohl aber durch Plasma. Die Gewinnung des Plasmas geschah in folgender Weise. Es wurde in ein paraffiniertes Gläschen $1 \mathrm{ccm}$ neutraler Kochsalzlösung gebracht und nach Kühlung auf $0^{0} \quad 10-20$ Tropfen Blut aus der Fingerbeere einfließen gelassen. Die Mischung wurde dann 10 Minuten unter möglichster Kühlung bei 3000 Umdrehungen zentrifugiert. Man erhält so ein verdünntes Plasma, dessen obere blutplättchenfreie Schicht, wenn sorgfältig gekühlt ist, nach dem Abheben spontan nicht gerinnt. Spült man nun mit diesem Plasma die mit Hirudin behandelten Plättchen, so bleiben sie unverändert. Läßt man nun den Rest des nicht abgehobenen Plasmas mit dem Sediment bei Zimmertemperatur etwa 15 Minuten stehen, und spült dann mit diesem Plasma, kurz ehe die Gerinnung beginnt, so tritt fast momentan gleichzeitig mit dem Auftreten der Fibrinfäden das typische Bild der Agglutination der Plättchen ein.

Da bei dem Erwärmen der gekühlten Blutflüssigkeit die bis dahin unversehrten Blutplättchen in derselben zerfallen, so kann man annehmen, daß durch den Zerfall eine Substanz in das Plasma kommt, welche nun auch die isolierten Plättchen 
agglutiniert. Es ist nach allem, was wir bisher über die Beteiligung der Blutplättchen bei der Gerinnung nach den Untersuchungen von Mor awitz, ${ }^{1}$ Schittenhelm und Bodong ${ }^{2}$ ) u.a. wissen, wahrscheinlich, daß diese Substanz ein Ferment ist. Es ist aber nicht identisch mit dem fertigen Gerinnungsferment selbst, sondern mit einer Vorstufe (Thrombogen), denn durch Serum, welches Gerinnungsferment enthält, zerfallen die isolierten Plättchen nicht. Es wird somit wahrscheinlich, daß die Blutplättchen durch ein Ferment, das von ihnen selbst abgegeben wird, zugrunde gehen und daß den $\mathrm{OH}-$ Ionen nur eine indirekte Wirkung zukommt, indem sie entweder das Ferment aktivieren oder den Eintritt oder die Abgabe des Fermentes ermöglichen.

Die Beobachtung, daß die Blutplättchen nach kurzer Behandlung mit Hirudinlösung durch Alkali zerfallen, bei längerer nicht, würde bei dieser Annahme wohl am einfachsten so gedeutet werden müssen, daß die Blutplättchen eine Zeitlang Ferment sezernieren, das bei Gegenwart von Hirudin von diesem gebunden wird. Wird das Hirudin durch Spülung entfernt, ehe die Fermentproduktion erschöpft ist, so tritt Zerfall ein.

Auch die Manganmethode spricht für die Annahme, daß das Proferment den Zerfall einleitet. Denn es ist wahrscheinlich, daß durch das Mangansalz das Proferment verändert oder beeinflußt wird. In diesem Zustande ist es weniger wirksam und kann dann die Blutplättchen nur langsam angreifen.

Als dritte Methode war die Spülung mit Wittepeptonlösung genannt. Sie unterscheidet sich dadurch wesentlich von der Hirudinmethode, daß auch nach sehr langer Behandlung mit der Peptonlösung bei nachfolgender Spülung mit alkalischer Salzlösung noch Zerfall eintritt. Das würde vielleicht durch die Annahme erklärt werden können, daß das Pepton die Blutplättchen lähmt, wodurch sie verhindert werden, Ferment zu sezernieren. Die lähmende Wirkung des Peptons zeigt sich deutlich bei der Beobachtung der amöboiden Bewegungen

1) Morawitz, Arch. f. klin. Med., Bd. LXXIX, S. 215.

2) Schittenhelm und Bodong, Arch. f. exper. Pathol. u. Pharmakol., Bd. LIV, S. 217. 
der Plättchen, wie weiter noch ausgeführt werden soll. Die beweglichen Blutplättchen kontrahieren sich nämlich rasch bei Behandlung mit Peptonlösungen.

Peroxyde wirken ähnlich wie Hirudin. Durch Plasma gehen die Plättchen zugrunde, aber nicht so rasch, wie bei der Hirudinmethode. Die Art der Schutzwirkung muß aber eine andere sein, wie beim Hirudin, da Peroxyde die Gerinnung nicht verhindern. Es ist vorläufig nicht möglich, etwas Sicheres über ihre Wirkungsweise auszusagen. Es wäre denkbar, daß sie den Herantritt des Fermentes an die Zelle oder eine Substanz in der Zelle verhindern.

\section{Amöboide Bewegungen und Kern der Blutplättchen.}

Der Nachweis, daß die Blutplättchen aus Kern und Protoplasma bestehen, und amöboider Bewegung fähig sind, ist schon früher von mir auf andere Weise geführt worden. ${ }^{1}$ ) Doch ist die Methode nicht so leicht und zuverlässig wie die, welche ich jetzt anwende. Sie besteht in der Isolierung der Blutplättchen mit Hilfe von peroxydhaltigen Lösungen. Wenn es auch gelingt, durch Behandlung mit reinen Kochsalzlösungen, denen etwas Peroxyd zugesetzt wird, die Plättchen am Leben zu erhalten, so ist es doch besser, noch Mangansalz zuzufügen, da das Peroxyd eine gewisse Zeit braucht, ehe es die Blutplättchen so weit verändert hat, daß das Ferment nicht mehr angreifen kann. Mangansalze besitzen aber, wie wir sahen, die Eigenschaft, die Fermentwirkung zu verlangsamen, ohne dabei lähmend auf die Blutplättchen zu wirken. Als einfachste und beste Untersuchungsflüssigkeit benutzte ich jetzt folgende Lösung. Kochsalz $0,75 \mathrm{~g}$, Mangansulfat $0,5 \mathrm{~g}$, Natriumcarbonat $0,01 \mathrm{~g}$, aq. dest. $100 \mathrm{ccm}$. Auf diese Lösung bringt man etwa 10 Tropfen Amylen ${ }^{2}$ ) und läßt abdunsten. Das Peroxyd bleibt dann in Lösung. Man kann auch umschütteln und das Amylen durch Kochen verjagen. Statt des Amylens kann man auch andere peroxydhaltige Substanzen zusetzen, z. B. Allylchlorid.

1) H. Deetjen, Virchows Arch., Bd. CLXIV.

2) In den Versuchen benutzte ich meist ein von der Firma Merck in Darmstadt bezogenes etwa $1 \mathrm{Jahr}$ altes Amylen. 
Recht gute Resultate bekommt man auch mit Wasserstoffsuperoxyd. Man setzt zu obiger Lösung $0,5 \mathrm{ccm}$ einer $1 \%$ igen Perhydrollösung. Doch zersetzen sich diese Lösungen ziemlich rasch, während Amylenlösungen einige Tage haltbar sind und auch wohl etwas besser die Blutplättchen am Leben halten.

Spült man mit dieser Lösung in der angegebenen Weise das aus der Fingerbeere entnommene Blut zwischen Deckglas und Objektträger aus gewöhnlichem Glas, so sieht man nach wenigen Minuten den Beginn der amöboiden Bewegungen. Die Blutplättchen breiten sich dabei am Glase aus und lassen deutlich zwei Substanzen unterscheiden, einen zentralen stark lichtbrechenden, runden Kern und ein hyalines Protoplasma. Dieses treibt zarte pseudopodienartige Fortsätze aus, deren Gestalt fortwährend wechselt. Die Veränderungen sind in der Regel langsam und träge, aber kontinuierlich.

Die Plättchen können sich bisweilen ganz außerordentlich stark am Glase ausbreiten, so daß derjenige, welcher die Blutplättchen nur in ihrem Ruhezustand gesehen hat, sie nicht wiedererkennt und sie für Lymphocyten oder dergleichen halten möchte. Es kann dann schwer werden, die Gestaltsveränderungen der zarten Gebilde zu verfolgen. Man kann sich aber dann leicht von der Lebensfähigkeit der Plättchen überzeugen, wenn man mit einer $2 \%$ igen Wit tepepton-Kochsalzlösung nachspült. Dann kontrahieren sich die Plättchen allmählich wieder und werden wieder $\mathrm{zu}$ rundlichen oder elliptischen Gebilden, wie wir sie im Ruhestadium zu sehen gewohnt sind. Ersetzt man die Peptonlösung wieder durch die Anfangslösung, so fangen sie von neuem an sich $z u$ bewegen. Die Blutplättchen behalten ihre Lebensfähigkeit stundenlang in der angegebenen Lösung und gehen nur allmählich unter dem Bilde der Quellung mit Randstellung des Kerns zugrunde.

Wichtig ist das Aussehen des Kerns. Er ist, wenn die Plättchen gut erhalten sind, stets rund und scharf vom Protoplasma abgegrenzt, von welchem er anscheinend durch einen schmalen hellen Hof geschieden ist. Sehr schön sind die Bilder, die man im fixierten und gefärbten Präparat bekommt. ${ }^{1}$ )

1) Ich werde die betr. Abbildungen an anderer Stelle veröffentlichen. 
Die Fixierung gelingt sehr leicht dadurch, daß man die Fixierungsflüssigkeit z. B. Osmiumsäure von der Kante zufließen läßt und dann weiter behandelt wie Trockenpräparate. Der Kern färbt sich sehr leicht mit allen sonst üblichen Kernfärbungsmitteln. Besonders schöne Bilder bekommt man bei Färbung nach Heidenhain und Giemsa. Es zeigt sich hierbei, daß wir es nicht nur mit einer Anhäufung von Kernsubstanz zu tun haben, sondern mit einem wirklichen morphologisch differenzierten Kern mit Kernmembran und Kerngerüst. Das Vorhandensein einer Kernmembran konnte auch von mir früher nicht nachgewiesen werden. Sie ist aber sehr deutlich an den nach Giemsa gefärbten Präparaten kenntlich, weniger gut hebt sie sich bei der Färbung nach Heidenhain ab. Man sieht sie als eine dunklere, verhältnismäßig breite Zone, welche die eigentliche Kernsubstanz vom Protoplasma scheidet. Wenn diese Hüllschicht auch wohl chemisch und morphologisch verschieden ist von der Kernmembran, wie wir sie sonst an Zellen kennen, so macht sie doch den Eindruck einer wirklich differenzierten Umhüllung der Kernsubstanz. Sie ist aber nur dann nachweisbar, wenn die Blutplättchen vollkommen intakt sind. Man kann sich davon am besten überzeugen, wenn man die Blutplättchen mit Manganlösungen ohne Zusatz von Peroxyd isoliert. Hier sieht man nämlich, wenn man etwa 10 Minuten nach Entnahme des Blutes fixiert, die Membran an den meisten Plättchen ebenso gut wie bei der Peroxydmethode; wenn man längere Zeit wartet, dann ist sie nicht mehr nachweisbar. Einzelne Exemplare behalten sie auch wohl längere Zeit. Gleichzeitig mit dem Verschwinden der Membran treten wesentliche Änderungen am Kern selbst ein. Er verliert sein starkes Lichtbrechungsvermögen, breitet sich immer mehr aus, die Konturen werden unregelmäßig, schließlich kann er fast vollkommen im Protoplasma sich auflösen, so daß man den Eindruck hat, als ob man kernlose Individuen vor sich hätte, denn das Protoplasma kann während dieses Auflösungsprozesses noch eine Zeitlang unverändert und sogar noch bewegungsfähig bleiben.

Der ganze Vorgang veranschaulicht sehr schön die Art des Angriffs des Fermentes auf die Zellen. Es scheint, als 
wenn das erste die Verflüssigung der Kernmembran ist. Alle jene Bilder, welche den Kern nicht rund und scharf abgegrenzt gegen das Protoplasma zeigen, sind als degenerative Veränderungen zu deuten. In guten Präparaten, wie ich sie jetzt fast regelmäßig bekomme, sieht man immer unter den vielen Tausenden von Plättchenindividuen, die sich im Präparate befinden, nur vereinzelte Exemplare, deren Kern nicht mehr scharf abgegrenzt ist.

Ein weiterer Beweis für die Kernnatur des Innenkörpers besteht darin, daß man ohne Schwierigkeit an mit Sublimat fixierten und nach Heidenhain gefärbten, und dann differenzierten Präparaten das Vorhandensein eines netzförmigen Kerngerüstes feststellen kann, das in seinem Aussehen sich nicht von den Bildern unterscheidet, die wir bei anderen Zellen kennen.

Ich muß auf Grund dieser Befunde noch schärfer als früher den von mir aufgestellten Satz, daß die Blutplättchen kernhaltige Zellen mit amöboider Bewegungsfähigkeit sind, aufrecht halten.

Wenn Autoren wie Weidenreich ${ }^{1}$ ) aus dem Grunde den Blutplättchen den Charakter von Zellindividuen mit Kern und Protoplasma absprechen, weil die beiden Substanzen nicht morphologisch getrennt wären, so liegt das nur daran, daß sie, wie auch die Abbildungen von Weidenreich zeigen, nicht vollkommen intakte, sondern schon zum Teil degenerierte Zellen vor sich hatten. Das ist sehr leicht möglich bei meiner früheren Methode. Das Gelingen der Präparate bei der Agarmethode scheint außer von der Beschaffenheit des benutzten Agar-Agar auch vom Einhalten einer ganz bestimmten Reaktion des Gemisches abhängig zu sein. Meine jetzige Methode ist in der Beziehung sehr viel weniger empfindlich.

\section{Blutplättchenzerfall und Blutgerinnung.}

Nachdem wir im vorhergehenden die Bedingungen des Zerfalls der isolierten Blutplättchen kennen gelernt haben, können wir jetzt versuchen, die Frage zu beantworten, warum

1) Weidenreich, Verhandl. d. anat. Ges. in Rostock, 1906. 
die Blutplättchen so rasch nach Verlassen des Blutes aus den Gefäßen zugrunde gehen, und die Blutgerinnung eintritt. Auf die nahen Beziehungen der Blutplättchen zur Gerinnung, die durch die Untersuchungen von Morawitz, ${ }^{1}$ ) Schittenhelm und Bodong ${ }^{2}$ ) u. a. einigermaßen klar gestellt sind, will ich hier nicht eingehen. Wir können als feststehend annehmen, daß das Gerinnungsferment im wesentlichen, wenn auch vielleicht nicht ausschließlich, den Blutplättchen seinen Ursprung verdankt, und daß beim Zerfall der Plättchen besonders reichliche Mengen des Fermentes resp. des Zymogens in das Blut übertreten. Worauf es uns ankommt, ist allein die Frage nach der Ursache dieses Zerfalls. Wir sahen, daß bei den isolierten Plättchen hierbei 2 Faktoren in Betracht kommen, eine fermentartige Substanz, die von den Plättchen selbst abgegeben wird, und Hydroxylionen; wobei es ungewiß bleiben muß, in welcher Weise die $\mathrm{OH}-$ Ionen wirken, ob sie das Ferment aktivieren oder die Abgabe des Fermentes ermöglichen. Jedenfalls enthalten die Blutplättchen selbst den einen Faktor, das Ferment, und es ist deshalb nur notwendig, zu untersuchen, ob auch die Anwesenheit von OH-Ionen in genügender Konzentration in dem aus der Ader gelassenen Blute sich nachweisen läßt. Wir wissen nun durch die eingehenden Untersuchungen von Friedenthal, ${ }^{3}$ ) Höber, ${ }^{4}$ ) Fränkel ${ }^{5}$ ) u. a., daß das Blut eine fast vollkommen neutrale Flüssigkeit ist. Das gilt aber streng genommen nur für Blut, ehe es mit Luft in Berührung gekommen ist. An der Luft entweicht Kohlensäure, und die Folge ist ein wenn auch geringer Überschuß von Hydroxylionen. Die Abhängigkeit der Reaktion des Blutes von dem Kohlensäuregehalt ergibt sich aus den Untersuchungen von Höber, er fand zuerst eine OH-Ionenkonzentration ent-

1) a. a. 0 .

2) a. a. 0 .

s) H. Friedenthal, Zeitschr. f. allgem. Physiol., Bd. I, S. 56, 1901; Bd. IV, S. 44, 1904.

4) R. Höber, Pflügers Arch., Bd. LXXXI, S. 522, 1900; Bd. XCIX, S. 572, 1903.

5) P. Fränkel, Pflügers Arch., Bd. XCVI, S. 601, 1903.

Hoppe-Seyler's Zeitschrift f. physiol. Chemie. LXIII. 
sprechend etwa einer $1 / 100000-n-N a O H$. Erst später, als er bei gleichzeitiger Durchleitung von $\mathrm{CO}_{2}-$ und $\mathrm{H}$-Mischungen die Prüfung wiederholte, bekam er die richtigen Werte bei Gasgemischen, die der $\mathrm{CO}_{2}$-Spannung des zirkulierenden Blutes entsprachen.

Auch die neueren Untersuchungen von Michaelis und Rona ${ }^{1}$ ) ergeben die Empfindlichkeit der Reaktion des Blutes gegen Veränderungen der $\mathrm{CO}_{2}$-Spannung. Auch durch die einfache Indikatorenmethode von Friedenthal kann man sich leicht davon überzeugen. Versetzt man frisches Serum mit Neutralrot so ist die Farbe orange. Leitet man nun über das Serum einen Strom von Luft, dem etwa 6 Volumprozent $\mathrm{CO}_{2}$ beigemengt sind, so geht die Farbe in die neutrale Rotfärbung über, um beim Stehenlassen an der Luft sich wieder in orange zu verwandeln. Es sind nur sehr geringe Abweichungen vom Neutralpunkt, um die es sich hier handelt, aber es scheint, daß in solchen Fällen, wo die Innehaltung des Neutralpunktes überhaupt von Bedeutung ist, es nicht auf die Größe der Abweichung, sondern überhaupt nur auf jede Änderung ankommt. Diese wird im zirkulierenden Blut in sehr vollkommener Weise für gewöhnlich verhindert. Sowie aber das Blut mit Luft in Berührung kommt, wird das Gleichgewicht durch Abgabe der Kohlensäure gestört. Daneben können noch andere Momente für das Anwachsen der Konzentration der $\mathrm{OH}-I$ Ionen in Betracht kommen, wie der von Hamburger ${ }^{2}$ ) nachgewiesene Austausch von Cl-Ionen des Plasmas gegen $\mathrm{CO}{ }_{3}$-Ionen der roten Blutkörperchen. Jedenfalls würde eine Konzentration der OH-Ionen, wie sie nach den Angaben von Höber und nach der Indikatorenmethode nachweisbar ist bei Gegenwart von Ca-Ionen, wie die zu Anfang mitgeteilten Versuche ergeben, durchaus genügen, um den Zerfall der Blutplättchen im Blute nach Entnahme des Blutes aus den Gefäßen zu erklären. Es würde demnach der Kohlensäureverlust, den das Blut an der Luft erleidet, ausreichend sein, um den Zerfall der Blutplättchen und damit auch das ras che Eintreten der Gerinnung zu bewirken. S. 316,1909 .

2) Hamburger, Osmotischer Druck und Ionenlehre, S. 303. 
$\mathrm{Daß}$ die Blutgerinnung vom Kohlensäuregehalt des Blutes beeinflußt wird, ist bekannt. Wir wissen, daß Erstickungsblut nicht gerinnt. Auch bei Blutergüssen in geschlossene Höhlen, wie Gelenke, Uterus usw., findet man das Blut häufig flüssig. Bekannt ist auch, daß beim Auffangen des Blutes unter Öl die Gerinnung ausbleibt. Man hat geglaubt, daß die Berührung mit fremdartigen Substanzen die Gerinnung beschleunige, und daß deshalb in vielen dieser Fälle, wenn diese Berührung fortfällt, das Blut flüssig bleibe. Das erklärt aber nur zum Teil den Befund. So gibt Hamburger ${ }^{1}$ ) an, $\mathrm{da} \beta$ es auch ohne Öl gelingt, Blut flüssig zu halten, wenn man es direkt aus dem Gefäße in Flaschen unter Vermeidung der Schaumbildung auffängt. Es liegt sehr viel näher, den Umstand, daß in dem genannten Falle die Kohlensäure nicht entweicht, für das Ausbleiben der Gerinnung hauptsächlich verantwortlich zu machen. Wie die Blutplättchen sich dabei verhalten, ist bisher nicht untersucht.

Bei doppelt unterbundenen Venen (vom Hund), in denen das Blut bekanntlich auch nicht gerinnt, wo aber die Gerinnung nach Eröffnung des Gefäßes rasch eintritt, konnte ich konstatieren, daß noch 2 Stunden nach der Operation die Blutplättchen vollkommen intakt waren.

Ich habe dann weiterhin Versuche angestellt, wie sich die Blutplättchen und die Gerinnungsfähigkeit verhalten, wenn man entweder das Blut unter Gemischen von $\mathrm{CO}_{2}$ und Luft oder bei Abschluß der Berührung mit Luft auffängt.

Bezüglich der Versuche, Blut unter Gemischen von Luft und Kohlensäure aufzufangen, möchte ich noch kein definitives Urteil abgeben. Es ist nämlich einigermaßen schwer, hier Fehlerquellen zu vermeiden. Die Versuche wurden so gemacht, daß beim Kaninchen das Blut aus der Carotis in ein Reagenzglas aus Quarz oder Jenaer Glas, das mit den Mischungen gefüllt war, aufgefangen wurde. Es ist aber schwer, beim Einbinden der Kanüle einmal Verluste an Gasgemisch zu vermeiden, und anderseits die Beimischung von Gewebe-

1) Hamburger, Osmotischer Druck und Ionenlehre, 1902, S. 267. 
saft aus der Arterie zu verhindern. Bei Füllung des Aufnahmegefäßes mit reiner Kohlensäure war das Blut ebenso rasch wie an der Luft geronnen, nämlich nach 15 Minuten.

Beim Auffangen unter einem Gemisch, das 15 Volumprozent $\mathrm{CO}_{2}$ enthielt, war das Blut nach $3 / 4$ Stunden noch vollkommen flüssig, nach 1 Stunde am Rande flockig, im Innern flüssig, nach $1 \frac{1}{2}$ Stunden zum größten Teil geronnen, aber nicht fest erstarrt. Der Kohlensäuregehalt wurde in der im Gasometer befindlichen Mischung bestimmt, er ist im Auffangegefä $ß$ voraussichtlich geringer. Andere Versuche gaben ähnliche Resultate, d. h. es wurde bei Gemischen, die 12 bis 1 ๖ Volumprozent $\mathrm{CO}_{2}$ enthielten, die Blutgerinnung verzögert, aber nicht vollkommen verhindert.

Leichter gelingt es, das Blut bei Vermeidung der Berührung mit Luft längere Zeit ungerinnbar zu halten. Es wurde $\mathrm{zu}$ diesem Zweck das Blut aus leicht gestauter Armvene in eine gutschließende Glasspritze aufgesogen. Das Blut bleibt dann etwa eine Stunde flüssig. Von Klinikern und Chirurgen, welche diese Art der Blutentnahme häufig machen, wurde mir gesagt, daß das Blut meist sehr rasch gerinne. Der Unterschied ist wohl darauf zurückzuführen, daß ich aus begreiflichen Gründen es vermied, die Spritze mit Soda auszukochen.

Wenn derselbe Versuch mit einer Spritze angestellt wird, deren Wände mit flüssigem Vaselin benetzt waren, so bleibt das Blut 2-3 Stunden flüssig; wurde ein Teil des Blutes nach 15 Minuten in ein paraffiniertes Reagenzglas gebracht, so gerann es nach 15 Minuten.

Läßt man nach der Blutentnahme noch die gleiche Menge Luft in die Spritze eintreten, so gerinnt das Blut nach 20 Minuten.

Die Blutplättchen waren immer intakt, solange das Blut flüssig war.

Wir sehen also, daß, wenn die Berührung des Blutes mit Luft vermieden wird, die Blutplättchen sehr lange vor dem Zerfall bewahrt bleiben. Es kann dabei kaum ein anderes Moment als die Verhinderung der Kohlensäureabgabe in Betracht kommen. Daß die Plättchen nicht dauernd sich intakt halten, kann einmal in Versuchsfehlern liegen. Es kann sein, daß die 
Benetzung der Glaswand mit Vaselin nicht vollkommen ist. Es brauchen ja nur an einer kleinen Stelle Blutplättchen mit dem Alkali des Glases in Berührung zu kommen, dann werden sie zerfallen und hierbei aktives Ferment abgeben, das nun weitere Blutplättchen zerstört. Es kann aber auch sein, daß nicht nur OH-Ionen, sondern auch andere Substanzen, allgemein gesagt, als Reiz wirken, durch welche der Austritt oder die Abgabe von Ferment möglich wird. Dafür würden ja manche Erfahrungen sprechen.

Jedenfalls spricht das Resultat dieser Versuche für die Richtigkeit des aufgestellten Satzes, daß der Kohlensäureverlust allein genügt, um den raschen Zerfall der Blutplättchen und damit das Eintreten der Gerinnung zu erklären. Es soll nicht gesagt werden, daß dieser Verlust immer die einzige Ursache der Blutgerinnung sei. Es ist ja sehr wohl möglich oder sogar wahrscheinlich, daß Gerinnungsferment auch noch von andern Zellen abgegeben werden kann; ebenso vielleicht auch ein Ferment, das die Blutplättchen angreift. In der Regel kommen aber diese Faktoren nicht in Betracht. Die Natur mußte es so einrichten, daß, um Verblutung zu vermeiden, möglichst rasch bei Verletzungen der Gefäße das Blut zur Gerinnung kommt. $\mathrm{Zu}$ diesem Zwecke sind offenbar die Blutplättchen adaptiert, indem bei ihrem Zerfall plötzlich große Mengen Ferment abgegeben werden. Man könnte deshalb wegen ihrer leichten Zerstörbarkeit die Blutplättchen auch als *Tryptocyten* bezeichnen, wodurch sie vielleicht etwas allgemeiner als durch den von Dekhuyzen eingeführten Ausdruck *Thrombocyten* charakterisiert werden. ${ }^{1}$ )

Es ist dies wohl nicht die einzige Funktion der Blutplättchen, aber doch eine sehr wesentliche.

Die Untersuchungen über die Ursachen des Zerfalls und der Lebenserhaltung der Blutplättchen beziehen sich nur auf die des menschlichen Blutes. Die Blutplättchen von Mäusen, Kaninchen, Hund verhielten sich zum Teil anders. Sie zer-

2) Will man die Blutplättchen in analoger Weise wie die übrigen Zellen des Blutes nach der Farbe benennen, müßte man sie schon als Chlorocyten wegen ihres grünlichen Glanzes im Ruhezustand bezeichnen. 
fallen nicht bei der Isolierung und Spülung mit alkalischen Salzlösungen. Vielleicht enthalten sie nur wenig oder leicht durch Behandlung mit Salzlösung zerstörbares Ferment. Daß das Gerinnungsferment, welches von den Blutplättchen der Säugetiere abgegeben wird, sehr rasch beim Waschen der Blutplättchen mit Kochsalzlösung unwirksam wird, weiß man schon aus den Untersuchungen von Morawitz, ${ }^{1}$ ) ebenso verhält sich das in ihnen vorhandene peptolytische Ferment. ${ }^{2}$ ) Dagegen konnte ich feststellen, daß die Blutplättchen vom Affen sich ebenso verhielten wie die des Menschen. Es ist von Wichtigkeit, diesen Unterschied $\mathrm{zu}$ kennen und genauer $\mathrm{zu}$ untersuchen. Eine Reihe von widersprechenden Angaben über das Verhalten, Aussehen und Natur der Blutplättchen wird möglicherweise durch diese Differenz erklärt.

\section{Methode der Untersuchung.}

Obwohl die Methode der Untersuchung im allgemeinen sehr einfach und leicht ausführbar ist, möchte ich noch auf einige Punkte aufmerksam machen, deren Nichtbeachten leicht zu Irrtümern und Mißlingen führen kann. Die Blutplättchen sind nämlich, das gilt besonders, wenn man die Bewegungen beobachten will, gegen manche Verunreinigungen der Gläser und Beimengungen der Lösung außerordentlich empfindlich. Wichtig ist zunächst die Art des destillierten Wassers. Wie dies beschaffen sein muß, wenn man die Wirkung des Alkalis untersuchen will, habe ich schon genauer auseinandergesetzt. Für die Beobachtung der amöboiden Bewegungen mit Mangan oder Peroxydzusatz wird man meist wohl mit dem in den Apotheken käuflichen oder in den Instituten hergestellten Wasser auskommen, und muß strengstens darauf geachtet werden, daß keine metallischen Beimengungen wie Kupfer im Wasser sind, und daß das Wasser nicht in Berührung mit Kautschuk kommt. Man bewahrt es also in Flaschen mit Glasstöpsel oder übergestülpter Glasschale auf. Vor allem darf bei der Destillation

i) a. a. 0 .

2) E. Abderhalden und H. Deetjen, Diese Zeitschrift, Bd. LIII, S. $280,1907$. 
natürlich keine Kautschukverbindung eingeschaltet sein nach dem, was über die Kautschukwirkung oben gesagt ist. Bei geringem Gehalt der im Kautschuk vorhandenen wirksamen Substanz in der Lösung bekommt man eventuell die Bewegungen ohne weiteres gut zu sehen, bei stärkerem tritt Quellung ein. Es scheint, als ob ganz minimale Spuren schon auf die Blutplättchen einwirken. Die zur Aufnahme der Lösungen benutzten Gläser müssen natürlich gut gereinigt sein. Ich habe eine Zeitlang Fehler dadurch gehabt, daß die Gläser zum Trocknen in der üblichen Weise auf ein Holzgestell gebracht waren. Es zeigte sich, daß dabei schädigende Stoffe vom Holz an das Glas abgegeben werden können. Man soll sie also, wenn man sie nicht selbst gereinigt hat, immer vor dem Gebrauch mit reinem Wasser ausspülen oder besser ausdämpfen. Beim Ausdämpfen hat man aber zu beachten, daß die Kochflasche nicht mit Gummipfropfen verschlossen werden darf. Mit Watte verschlossene und durch trockene Hitze sterilisierte Gläser enthalten meist Produkte der trockenen Destillation, gereinigte Watte reagiert gewöhnlich sauer durch den beim Entfetten benutzten Äther. Äther selbst enthält, wenn er am Licht gestanden hat, außer anderen Verunreinigungen, reichlich Peroxyd, ist also dashalb zum Reinigen nicht zu verwenden. Es sind in jedem Laboratorium meist eine Fülle von Möglichkeiten der Verunreinigung einer Lösung, die, obwohl sie für gewöhnlich nicht in Betracht kommen, die Untersuchung der so äußerst empfindlichen Blutplättchen erschweren können.

Besonders machen Verunreinigungen sich geltend bei den zur Untersuchung benutzten Objektträgern und Deckgläsern. Da die Blutplättchen sich an diesen dicht anlegen, können auch Spuren fremdartiger Substanzen wirksam sein. Ich reinige die Gläser jetzt folgendermaßen. Einbringen der ungebrauchten Gläser in reine Salzsäure für einige Stunden, Abwaschen jeden Glases einzeln unter der Wasserleitung, dann noch Aufbewahren in destilliertem Wasser mehrere Stunden oder Tage, und Abtrocknen mit reinem Filtrierpapier. Vor dem Gebrauch werden die Gläser dann noch erhitzt, Objektträger direkt über der Flamme, Deckgläschen auf Asbest oder Glimmerscheibe. Gebrauchte Gläser 
müssen mit konzentrierter Schwefelsäure 24 Stunden oder länger gereinigt werden. Es ist besonders darauf zu achten, daß keine Säurereste am Glase zurückbleiben, was leicht vorkommen kann, wenn man die Gläser en masse reinigt.

Die Zusammensetzung der Lösung zur Untersuchung der amöboiden Bewegungen ist folgende

$\begin{array}{ll}\text { Mangansulfat } & 0,5 \\ \text { Chlornatrium } & 0,75 \\ \text { Natriumbicarbonat } & 0,01\end{array}$

Auf diese Lösung bringt man etwa 10 Tropfen Amylen (Trimethyläthylen), ${ }^{1}$ ) läßt dieses abdunsten und schüttelt dann um.

Der Zusatz von Natriumbicarbonat erfolgt, weil altes Amylen sauer reagiert, das Peroxyd aber in saurer Lösung unwirksam ist. Die Lösung hält sich mehrere Tage wirksam, ein allmählich eintretender Niederschlag von $\mathrm{Mn}(\mathrm{OH})_{2}$ schadet nicht. Die Menge des Amylens richtet sich nach dem Peroxydgehalt, es ist deshalb schwer möglich, bestimmte Angaben darüber zu machen, doch schadet ein geringer Überschuß nicht. Ganz frisch hergestelltes Amylen(betr.d. Darstellung cf. Sch midt, Lehrbuch d. pharmaz. (hemie) wird rasch aktiv, wenn eine kleine Menge in einer größeren mit Luft oder Sauerstoff gefüllten Flasche dem Licht ausgesetzt wird. Man isoliert die Blutplättchen durch Spülung mit dieser Lösung, wie auf Seite 2 angegeben. Es genügt die Beobachtung bei Zimmertemperatur.

Statt des Amylens kann man auch andere Peroxyde nehmen. Sehr bequem, weil leicht erhältlich, ist Wasserstoffsuperoxyd (Perdydrol). Von einer $1 \%$ igen $\mathrm{H}_{2} \mathrm{O}_{2}$-Lösung setzt man $0,5 \mathrm{ccm}$ zu obiger Salzlösung. Diese Lösung ist nicht so haltbar wie die Amylenlösung, kommt aber sonst dieser in der Brauchbarkeit ziemlich nahe. Zur Fixierung empfehle ich 1\%ige Osmiumsäure, man kann dann alle Färbemethoden gleich gut anwenden, z. B. nach Heidenhain mit Eisenhämatoxylin oder nach Giemsa mit der für Spirochätenfärbung gebräuchlichen Lösung. Für die Darstellung der Kernstrukturen ist die Fixiernng mit konzentrierter wässriger Sublimatlösung vorzuziehen.

1) Von E. Merck (Darmstadt) bezogen. 


\section{Zusammenfassung.}

Die Blutplättchen des menschlichen Blutes lassen sich leicht zwischen Deckglas und Objektträger durch Spülung mit Kochsalzlösung isolieren. Sie zerfallen dabei rasch in «typischer * Weise. Bei Benutzung von Deckgläsern und Objektträgern aus Quarz und vollkommen neutralen Salzlösungen bleiben sie intakt. Bei Gegenwart geringster Mengen von Alkali in der Spülflüssigkeit gehen sie auch auf Quarzgläsern zugrunde, und zwar ist die Konzentration der Hydroxylionen, welche ausreicht, um den Zerfall einzuleiten: $\mathrm{C}_{\mathrm{OH}}=1 \cdot 10^{-5}$. Bei gleichzeitiger Gegenwart von $\mathrm{Ca}: \mathrm{C}_{\mathrm{OH}}=1 \cdot 10^{-6}$. Ebenso bewirken H-Ionen den Zerfall in einer Konzentration von $\mathrm{C}_{\mathrm{H}}=2 \cdot 10^{-4}$.

Die Wirkung der Hydroxylionen ist eine indirekte, sie beeinflussen ein Ferment oder ermöglichen die Abgabe eines Fermentes, welches die Blutplättchen zum Zerfall bringt. Es ergibt sich dies daraus, daß man unter geeigneten Bedingungen auch bei Gegenwart von Alkali den Zerfall verhindern kann. Als solche Mittel werden angeführt Hirudin, Salze der Manganreihe, Wittepepton und Peroxyde.

Die Hirudinversuche führen zu der Annahme, daß die Blutplättchen selbst das Ferment sezernieren, welches sie zerstört. Mit Hirudinlösungen behandelte Blutplättchen gehen nicht durch Alkali, wohl aber durch Plasma zugrunde. Das zerstörende Ferment ist nicht identisch mit dem Gerinnungsferment, vielleicht aber mit dem Proferment.

Bei Anwesenhett von Salzen der Manganreihe in der Spülflüssigkeit wird der Zerfall der Plättchen nicht vollkommen verhindert, aber sehr verzögert. Mangansalze verhindern die Blutgerinnung und zwar wahrscheinlich durch Veränderung des Profermentes.

Witt epepton lähmt die Blutplättchen, es kommt dann nicht zur Abgabe des Fermentes.

Peroxyde verhindern den Zerfall der isolierten Blutplättchen vollkommen. Über die Art der Wirkung läßt sich Bestimmtes nicht aussagen. Es ist möglich, daß nicht das Ferment, sondern die Substanz in den Blutplättchen, an welche das Ferment angreift, durch Peroxyde verändert wird. 
Die Peroxydmethode gestattet, die Lebenseigenschaften der Blutplättchen bequem zu untersuchen. Es ergibt sich, daß die Blutplättchen einen Kern mit Kernmembran und Kerngerüst und die Fähigkeit zu amöboiden Bewegungen besitzen.

Der Zerfall der Blutplättchen nach Entnahme des Blutes aus den Gefäßen ist in der Hauptsache auf den Verlust der Kohlensäure und die dadurch bedingte Änderung der Reaktion des Blutes zurückzuführen. Jedenfalls genügt diese Änderung der Reaktion, um allein schon den Zerfall zu erklären. Die Blutplättchen der Säugetiere verhalten sich anders bei Isolierung gegen Alkali als die vom Menschen, dagegen zeigen Affenblutplättchen das gleiche Verhalten. 